\title{
Stage II Nasal Cavity Cancer AJCC v6 and v7
}

National Cancer Institute

\section{Source}

National Cancer Institute. Stage II Nasal Cavity Cancer A/CC v6 and v7. NCI Thesaurus.

Code C6012.

Stage II includes: T2, N0, M0. T2: Tumor invading two subsites in a single region or extending to involve an adjacent region within the nasoethmoidal complex, with or without bony invasion. N0: No regional lymph node metastasis. M0: No distant metastasis. (AJCC 6th and 7th eds.) 